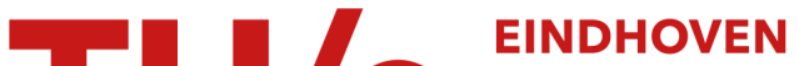 UNIVERSITY OF TECHNOLOGY
}

\section{Anode pattern formation in atmospheric pressure air glow discharges with water anode}

Citation for published version (APA):

Verreycken, T., Bruggeman, P. J., \& Leys, C. (2009). Anode pattern formation in atmospheric pressure air glow discharges with water anode. Journal of Applied Physics, 105(8), 083312-1/4. [083312].

https://doi.org/10.1063/1.3117223

DOI:

$10.1063 / 1.3117223$

Document status and date:

Published: 01/01/2009

Document Version:

Publisher's PDF, also known as Version of Record (includes final page, issue and volume numbers)

Please check the document version of this publication:

- A submitted manuscript is the version of the article upon submission and before peer-review. There can be important differences between the submitted version and the official published version of record. People interested in the research are advised to contact the author for the final version of the publication, or visit the $\mathrm{DOI}$ to the publisher's website.

- The final author version and the galley proof are versions of the publication after peer review.

- The final published version features the final layout of the paper including the volume, issue and page numbers.

Link to publication

\section{General rights}

Copyright and moral rights for the publications made accessible in the public portal are retained by the authors and/or other copyright owners and it is a condition of accessing publications that users recognise and abide by the legal requirements associated with these rights.

- Users may download and print one copy of any publication from the public portal for the purpose of private study or research.

- You may not further distribute the material or use it for any profit-making activity or commercial gain

- You may freely distribute the URL identifying the publication in the public portal.

If the publication is distributed under the terms of Article $25 \mathrm{fa}$ of the Dutch Copyright Act, indicated by the "Taverne" license above, please follow below link for the End User Agreement:

www.tue.nl/taverne

Take down policy

If you believe that this document breaches copyright please contact us at:

openaccess@tue.nl

providing details and we will investigate your claim. 


\title{
Anode pattern formation in atmospheric pressure air glow discharges with water anode
}

\author{
T. Verreycken, ${ }^{1}$ P. Bruggeman, ${ }^{1,2, a)}$ and C. Leys ${ }^{1}$ \\ ${ }^{1}$ Department of Applied Physics, Ghent University, Jozef Plateaustraat 22, B-9000 Ghent, Belgium \\ ${ }^{2}$ Department of Electronic and Electrical Engineering, Loughborough University, Loughborough, \\ Leicestershire LE11 3TU, United Kingdom
}

(Received 12 December 2008; accepted 14 March 2009; published online 28 April 2009)

\begin{abstract}
Pattern formation in the anode layer at a water electrode in atmospheric pressure glow discharges in air is studied. With increasing current a sequence of different anode spot structures occurs from a constricted homogeneous spot in the case of small currents to a pattern consisting of small distinct spots for larger currents. The dependence of the number of spots on the current is (18.5 $+0.4 N) \mathrm{mA}$ with $N$ the number of spots. The spots group together and form stripe patterns. Disappearance of the spots with increasing conductivity of the electrode seems to indicate that mechanisms of electrical nature govern the phenomenon. Similarities and differences with other experiments and models revealing pattern formation in glow discharges are discussed. (C) 2009 American Institute of Physics. [DOI: 10.1063/1.3117223]
\end{abstract}

\section{INTRODUCTION}

As in many physical, chemical, and biological systems, self-organization is a common phenomenon in gas discharge physics. ${ }^{1}$ The considerable amount of papers on this topic illustrates the interest in the plasma community for selforganization, which typically occurs in the anode or cathode layer. $^{2-8}$ According to Müller, ${ }^{9}$ patterns of spots occur if a bistable layer, characterized by an S-shaped voltage-current density characteristic, is in contact with a resistive medium. The resistive medium is necessary to stabilize a system of spots, i.e., to allow a potential difference at the electrode surface. In the experiment presented in the current paper, a water anode is used as resistive electrode. At present, a complete understanding of the mechanisms responsible for the formation of multiple spots is missing. Simulation studies of pattern formation can basically be divided into two approaches. ${ }^{2}$ The first approach is phenomenological and describes the phenomenon with a set of general reactiondiffusion equations of the form

$$
\frac{\partial \boldsymbol{q}}{\partial t}=\mathbf{D} \Delta \boldsymbol{q}+\boldsymbol{R}(\boldsymbol{q})
$$

where the vector $\boldsymbol{q}(\boldsymbol{x}, t)$ represents a set of functions describing space distributions, $\mathbf{D}$ is a diagonal matrix of diffusion coefficients and $\boldsymbol{R}$ accounts for all local reactions. This general set of equations can be used to obtain the spatial patterns observed in different research fields. ${ }^{9}$ The basic equations that describe a gas discharge (i.e., the continuity equations of the particles and the Poisson equation) can be fitted in this general set of reaction-diffusion equations. ${ }^{7,10}$ The second approach consists of detailed numerical simulations of the discharge physics. ${ }^{3,8,11}$ The model used in Ref. 11, which comprises a conservation equation for electrons, a conservation equation for a single ion species, and the Poisson equa-

\footnotetext{
a) Author to whom correspondence should be addressed. Electronic mail: peter.bruggeman@ugent.be.
}

tion, shows that these basic plasma processes can account for pattern formation. Although models as the one presented in Ref. 11 show circular pattern formation, it is not possible to explain experimental results entirely, as multiple spot formation is often observed, which requires a three-dimensional (3D) model and the models up to now are two-dimensional (axisymmetric).

Recently there has been an increased interest in plasma in and in contact with liquid for biomedical and environmental applications (e.g., Refs. 12-18). Several of these papers deal with dc-excited atmospheric pressure glow discharges between a metallic cathode and a liquid anode. ${ }^{19-21}$ Miao et $a l .{ }^{19}$ observed ringlike patterns. Wilson et al. ${ }^{20}$ observed a self-rotating low current atmospheric pressure discharge between a metallic cathode and a water anode, giving rise to a ringlike anode spot similar to the one observed by Miao et al. ${ }^{19}$ Bruggeman et al. ${ }^{21}$ studied atmospheric pressure glow discharges with a liquid anode by means of electrical and optical diagnostics. The pattern formation on the liquid anode is investigated in the present paper in the same configuration as in Ref. 21.

\section{EXPERIMENTAL SETUP}

The experimental setup is shown schematically in Fig. 1. A cone shaped stainless steel electrode with a tip radius of curvature of $1 \mathrm{~mm}$ is attached to a micrometer screw above a liquid reservoir, the latter having a volume of $660 \mathrm{ml}$. Distilled water and sodium chloride solutions with variable concentrations are used as liquid electrode. In the paper not the concentrations but the corresponding conductivity of the liquid electrode at room temperature is always given. The grounded electrode at the bottom of the liquid electrode is made of stainless steel. For currents of up to $30 \mathrm{~mA}$, a ballast resistor of $30 \mathrm{k} \Omega$ is used. The interelectrode distance is fixed at $5 \mathrm{~mm}$. Pictures of the anode patterns are obtained by a Hamamatsu intensified charge-coupled device (ICCD) (C8484) with sensitivity in the UV and visible region. The 


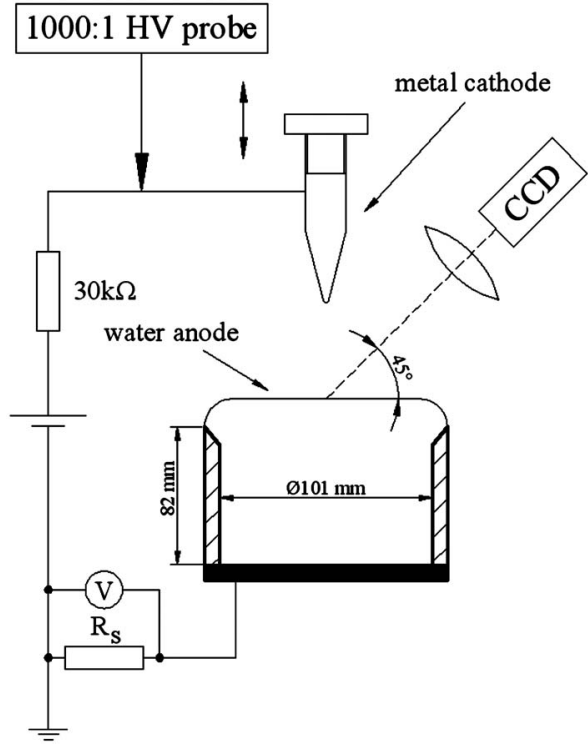

FIG. 1. Experimental setup.

angle between the ICCD line of sight and the water electrode surface is $45^{\circ}$. For further details the reader is referred to Ref. 21. For measurements in the current range of 30-120 $\mathrm{mA}$, the stainless steel electrode is replaced by a watercooled tungsten electrode with a radius of curvature of 1.6 $\mathrm{mm}$ to prevent excessive heating of the metal electrode at higher powers. The ballast resistor is reduced to $11 \mathrm{k} \Omega$ in this case.

\section{RESULTS AND DISCUSSION}

The dependence of the pattern formation on the current and conductivity of the liquid electrode is investigated. With increasing current, several transitions are generally observed. At low currents, between 5 and $10 \mathrm{~mA}$, the discharge is constricted at the anode to a small homogeneous spot with high current density [Fig. 2(a)]. When the current is increased, the anode spot enlarges and at about $10 \mathrm{~mA}$, a ringlike structure becomes visible [Fig. 2(b)]. In the range between 10 and $20 \mathrm{~mA}$, deformations of the ring occur and the pattern is unstable [Figs. 2(c) and 2(d)]. For a discharge
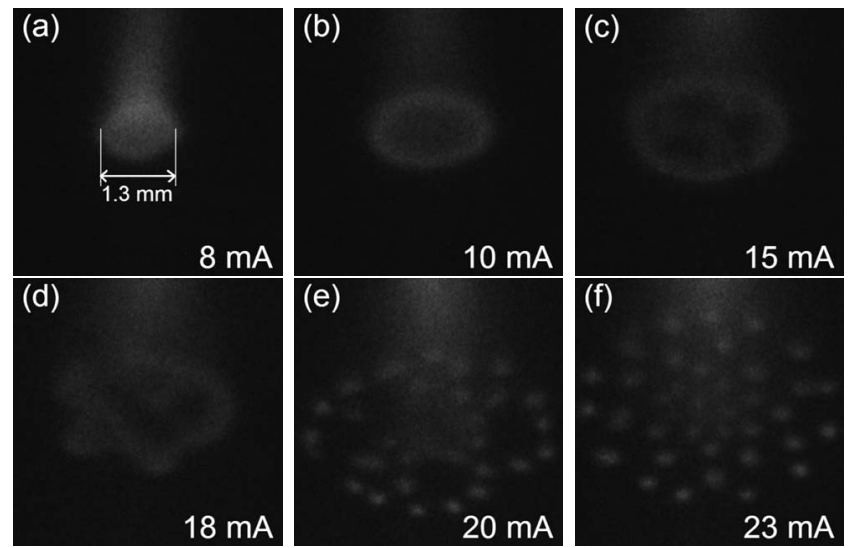

FIG. 2. Example of the observed pattern transitions in the current range of 5-30 mA. Because it is a low intensity discharge, the contrast has been increased. $\sigma=10 \mu \mathrm{S} / \mathrm{cm}$; exposure time $=500 \mu \mathrm{s}$.

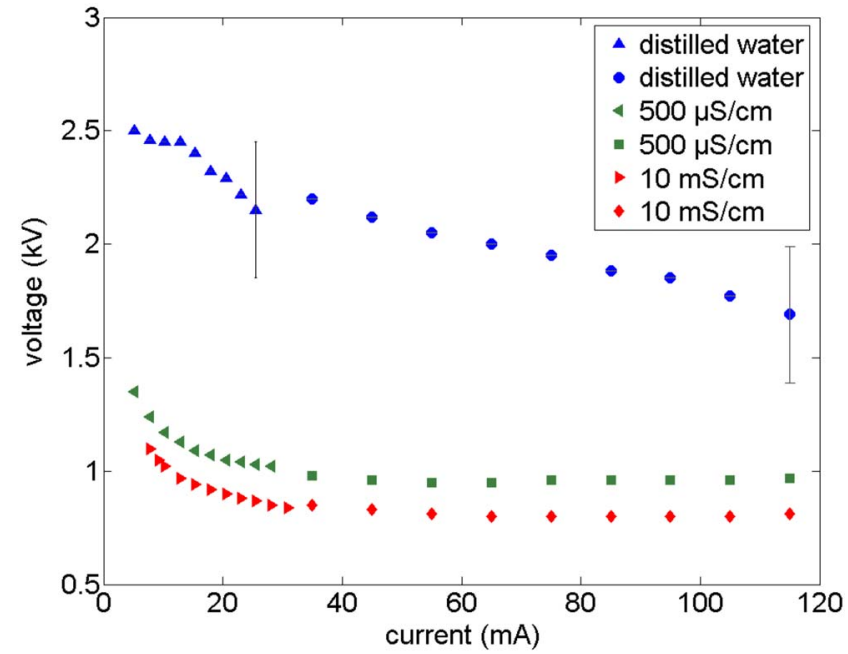

FIG. 3. (Color online) Current-voltage characteristic for different water electrode conductivities.

burning at currents higher than $20 \mathrm{~mA}$, distinct spots are clearly observed in this current range for water electrical conductivities smaller than $1 \mathrm{mS} / \mathrm{cm}$ [Fig. 2(e)]. These spots are distributed more regularly as the current increases [Fig. 2(f)]. In the case of conductivities of 1 and $3 \mathrm{mS} / \mathrm{cm}$, anode spots appear above $28 \mathrm{~mA}$, and for the case of $10 \mathrm{mS} / \mathrm{cm}$ even no distinct small spots are observed below $30 \mathrm{~mA}$, clearly indicating that the conductivity of the electrode is the determining factor to allow pattern formation.

In Fig. 3 the current-voltage characteristic is shown for different conductivities. There is a clear descending trend in voltage with increasing conductivity. Due to a change in liquid properties in time (such as conductivity) in the case of distilled water, the voltage drops. ${ }^{16}$ In Fig. 4 the anode potential drop at a current of $25 \mathrm{~mA}$ is plotted as a function of water electrode conductivity. The anode potential drop is determined by measuring the voltage at different interelectrode distances and taking the extrapolation to zero interelectrode distance. In this estimation the influence of the cathode voltage drop [269 V (Ref. 22)], the voltage across the shunt

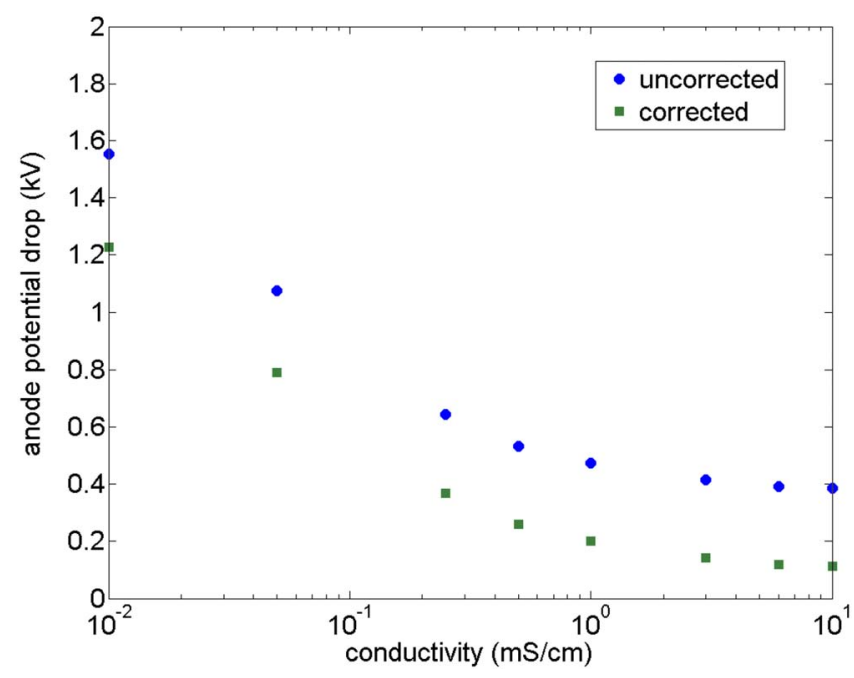

FIG. 4. (Color online) Anode potential drop as a function of water electrode conductivity at a constant current of $25 \mathrm{~mA}$. 


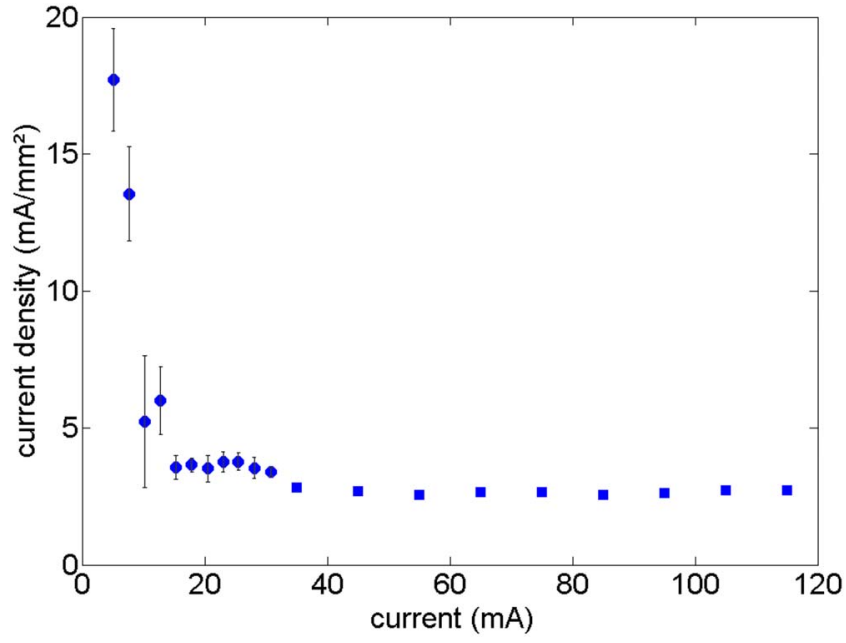

FIG. 5. (Color online) Current density as a function of current for a water electrode with a conductivity of $500 \mu \mathrm{S} / \mathrm{cm}$.

resistance, and the voltage across the water are taken into account. The decrease in voltage with increasing conductivity shown in Fig. 3 can be explained due to a change in equivalent resistance of the water electrode, a drop in temperature of the plasma with decreasing current, a change in anode/cathode voltage drop, and constriction of the positive column. For details the reader is referred to Ref. 21. The anode voltage drop in Fig. 4, corrected for the voltage across the water, has a descending trend similar to the currentvoltage characteristic. The cathode voltage drop is assumed constant as it is unknown if the cathode voltage drop is also depending on the current in this case.

In Fig. 5 it is seen that for the case of a liquid electrode conductivity of $500 \mu \mathrm{S} / \mathrm{cm}$, the current density is significantly higher for small currents than for currents above 15 $\mathrm{mA}$ for which it becomes constant (approximately $3 \mathrm{~mA} / \mathrm{mm}^{2}$ ). For these higher current densities no stable pattern formation is observed. The determination of the current density by the visible diameter of the anode spot is clearly only an estimate especially for an inhomogeneous anode spot. In Fig. 6 the increase in anode spot diameter is shown. It has a dependence of $0.81 \sqrt{I}-1.05$. As a consequence the surface of the anode spot is in proportion to the current, which is typical for a glow discharge.

In some cases deviations from the generally observed patterns occur. For example, when the water electrode has a conductivity of $500 \mu \mathrm{S} / \mathrm{cm}$, the constricted anode spot changes at $9 \mathrm{~mA}$ into something that looks like a three-blader boomerang [Fig. 7(a)]. In the range between 10 and $20 \mathrm{~mA}$, rosettelike structures are formed for this conductivity, as well as in the case of $3 \mathrm{mS} / \mathrm{cm}$ [Fig. 7(b)]. Sometimes in the latter case even concentric circles are observed [Fig. 7(c)]. For an electrical conductivity of $10 \mathrm{mS} / \mathrm{cm}$, only a large homogeneous anode spot with a more intense ring on the outside is seen for currents between 23 and $30 \mathrm{~mA}$, again indicating

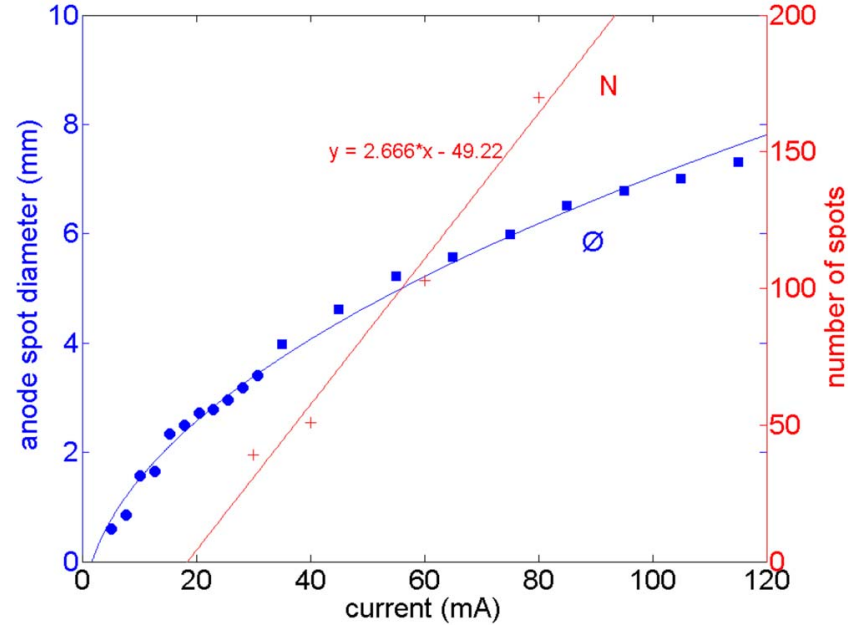

FIG. 6. (Color online) Anode spot diameter and number of spots as a function of current for a water electrode with a conductivity of $500 \mu \mathrm{S} / \mathrm{cm}$.

that the conductivity of the electrode is the determining factor in pattern formation. For currents in the range of 10-20 $\mathrm{mA}$ for the same conductivity, the anode spot splits up into two, three, or four separate spots instead of increasing its diameter with increasing current as shown in Fig. 2 [Figs. $7(\mathrm{~d})$ and 7(e)]. There is no clear difference in voltage for these different modes; only variations of at most $0.03 \mathrm{kV}$ (3\%) occurred, which could also be due to the discharge not being perfectly stable.

The pattern formation is investigated in the current range between 30 and $120 \mathrm{~mA}$. From Fig. 8 it is seen that the increase in anode spot diameter with increasing current (Fig. 6) is accompanied by an increase in the number of spots. The current carried by each spot is estimated from the number of spots as a function of current (Fig. 6). The dependence of the current on the number of spots is $(18.5+0.4 N) \mathrm{mA}$, with $N$ the number of spots. This current per spot is significantly smaller than observed in the case of Müller ${ }^{9}$ who obtained values of $20 \mathrm{~mA}$ per spot. However no clear reference to the conductivity of the resistive electrode is made in Ref. 9. In Fig. 8(d) it can also be seen that the anode patterns sometimes have spiral arms. These patterns are rotating, as is found by taking images at a frame rate of $44 \mathrm{~Hz}$. The direction of rotation appears to be arbitrary and sometimes even changes. Wilson et al. ${ }^{20}$ attributed rotation to the production of electronegative species poisoning the discharge.

In Fig. 9 patterns are shown for different conductivities and exposure times of the ICCD. The stripe patterns at larger exposure times are composed of individual small spots. When the conductivity of the water electrode increases, the pattern of radial stripes changes into a more homogeneous middle part with encircling stripes. This homogeneous middle part could be due to the light emission from the positive column, making it impossible to have a clear view on
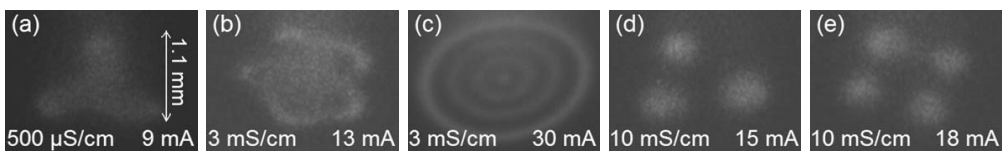

FIG. 7. Some peculiar cases of pattern formation. The conductivity of the water electrode is indicated on the left and the current on the right hand side of the image. The exposure time is $500 \mu$ s for all images. 

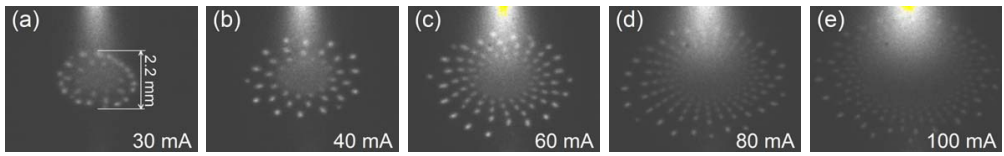

FIG. 8. (Color online) Anode patterns in the case of water with electrical conductivity of $500 \mu \mathrm{S} / \mathrm{cm}$ in the current range of $30-100 \mathrm{~mA}$. The exposure time is $500 \mu \mathrm{s}$.

the core of the spot. From the figure it can also be seen that the anode spot diameter decreases with increasing conductivity.

If images are taken with exposure times between 1 and $100 \mu \mathrm{s}$, the same number of spots is observed, indicating that the spots clearly coexist and that the pattern is not made by a single or a few filaments moving across the water surface.

Due to the dynamic nature of the water surface it is difficult to isolate the specific nature of the mechanism causing spot formation. As spot formation appears in very different background gases, from noble gases ${ }^{5}$ to air, and a resistive electrode is required, mechanisms of electrical nature seem to be on the basis of the phenomenon. However, full 3D models of the glow discharge taking into account air chemistry are necessary to unravel the detailed mechanisms of the phenomenon.

\section{CONCLUSION}

Anode pattern formation in atmospheric pressure glow discharges with a water anode is studied in this paper. With increasing current a sequence of different anode spot structures occurs from a constricted homogeneous spot in the case
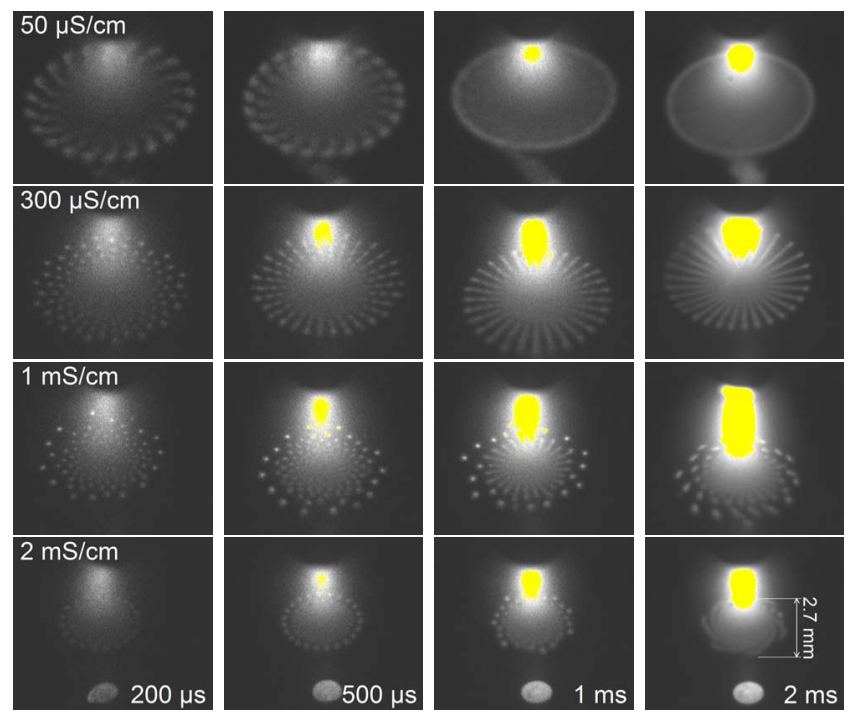

FIG. 9. (Color online) Overview of the anode patterns with different water electrical conductivities at $70 \mathrm{~mA}$. The exposure time and the water electrical conductivity are indicated in the figure. The images have the same gain for the same exposure times. of small currents to a pattern consisting of small distinct spots for larger currents. The spots group together and form stripe patterns that are seen at larger time scales. The anode spot diameter increases with decreasing water electrical conductivity and increasing discharge current. Disappearance of the spots with increasing conductivity of the electrode seems to indicate that mechanisms of electrical nature rather than chemical nature govern the phenomenon.

\section{ACKNOWLEDGMENTS}

One of the authors (P.B.) acknowledges the funding by a PhD fellowship of the Research Foundation-Flanders (FWO-Vlaanderen). The funding by the Interuniversity Attraction Poles Program of the Belgian Science Policy (Project No. PSI-P6/08) is also acknowledged.

${ }^{1}$ H.-G. Purwins, H. U. Bodeker, and A. W. Liehr, Proceedings of the Experimental Chaos: 8th Experimental Chaos Conference, Florence, Italy, 14-17 June 2004 (unpublished).

${ }^{2}$ M. S. Benilov, Phys. Rev. E 77, 036408 (2008).

${ }^{3}$ I. R. Rafatov, D. D. Šijačić, and U. Ebert, Phys. Rev. E 76, 036206 (2007).

${ }^{4}$ E. L. Gurevich, Y. A. Astrov, and H.-G. Purwins, J. Phys. D 38, 468 (2005).

${ }^{5}$ K. H. Schoenbach, M. Moselhy, and W. Shi, Plasma Sources Sci. Technol. 13, 177 (2004).

${ }^{6}$ C. Strümpel, Y. A. Astrov, and H.-G. Purwins, Phys. Rev. E 65, 066210 (2002).

${ }^{7}$ R. S. Islamov, Phys. Rev. E 64, 046405 (2001).

${ }^{8}$ R. S. Islamov and E. N. Gulamov, IEEE Trans. Plasma Sci. 26, 7 (1998).

${ }^{9}$ K. G. Müller, Phys. Rev. A 37, 4836 (1988).

${ }^{10}$ M. S. Benilov, Phys. Rev. A 45, 5901 (1992).

${ }^{11}$ P. G. C. Almeida and M. S. Benilov, 19th Europhysics Sectional Conference on the Atomic and Molecular Physics of Ionized Gases (ESCAMPIG), Granada, Spain, 15-19 July 2008 (unpublished).

${ }^{12}$ B. R. Locke, M. Sato, P. Sunka, M. R. Hoffmann, and J.-S. Chang, Ind. Eng. Chem. Res. 45, 882 (2006).

${ }^{13}$ P. Bruggeman and C. Leys, J. Phys. D 42, 053001 (2009).

${ }^{14}$ X. P. Lu and M. Laroussi, J. Phys. D 36, 661 (2003).

${ }^{15}$ P. Bruggeman, L. Graham, J. Degroote, J. Vierendeels, and C. Leys, J. Phys. D 40, 4779 (2007).

${ }^{16}$ P. Bruggeman, E. Ribezl, A. Maslani, J. Degroote, A. Malesevic, R. Rego, J. Vierendeels, and C. Leys, Plasma Sources Sci. Technol. 17, 025012 (2008).

${ }^{17}$ J. F. Kolb, R. P. Joshi, S. Xiao, and K. H. Schoenbach, J. Phys. D 41, 234007 (2008).

${ }^{18}$ X. P. Lu, J. Appl. Phys. 102, 063302 (2007).

${ }^{19}$ S. Y. Miao, S. Ren, D. Z. Wang, Y. T. Zhang, B. Qi, and Y. N. Wang, IEEE Trans. Plasma Sci. 36, 126 (2008).

${ }^{20}$ A. Wilson, D. Staack, T. Farouk, A. Gutsol, A. Fridman, and B. Farouk, Plasma Sources Sci. Technol. 17, 045001 (2008).

${ }^{21}$ P. Bruggeman, J. Liu, J. Degroote, M. G. Kong, J. Vierendeels, and C. Leys, J. Phys. D 41, 215201 (2008).

${ }^{22}$ Y. P. Raizer, Gas Discharge Physics (Springer-Verlag, Berlin, 1987). 